\title{
READING BODY, READING SOCIETY: BODY AS THE MICROCOSM OF SOCIETYIN ANDREW MCGAHAN'S NOVEL PRAISE
}

\author{
Inayatul Fariha \\ Universitas Negeri Malang \\ inayatul.fariha.fs@um.ac.id
}

\begin{abstract}
This article discusses the discourse of the body which is represented in the Australian novel entitled Praise, written by Andrew McGahan. It focuses on how the experience of the body reflects and represents the society in which it exists through a set of metaphors. There are two aspects discussed in this article. The first is the power relationship represented through alcoholism and sexuality, and the second is how the disease inflicted in the bodies represent the "destruction" of the society. The analysis shows that the bodily experiences of the main characters in the novel represents the discourse of complex power relationship that includes patriarchy, colonialism and capitalism in the contemporary society. The power invades and corrupts the body and the society and brings disorder. The corruption results in the disease that inflicts the characters, which ruin their systemic function. The "destruction" of the body represents the degradation of the society. Through the metaphors, the author successfully presents what so called "grotesque realism" and strips off the mask of the materialised society and demonstrate the dark side of human life in the contemporary culture.
\end{abstract}

Keywords: Andrew McGahan, Praise, Reading Body and Society, Sexuality and Power Relation

\section{INTRODUCTION}

Throughout the century the image of bodies has been the subject that fascinates the society. Human body contains mystery that curious human mind always questions. Human body has been the subject of study and analysis for the physician. Artisan's fascination about human body is expressed through their works of art. As human body is presented and represented, the body acquire meaning as it present engagement with various range of social concern within the context of culture and politics. From the beginning, knowledge has been closely associated to reading the social body.

The Australian award winning novel Praise, written by Andrew McGahan is one of the many cultural text that depict body as subject matter. Set in 1990's Brisbane, this novel depicts the experience of a young failed writer named Gordon Buchanan. His life changes after he meets Cynthia and lives with her. Cynthia was an alcoholic and sex addict who has had prolific sexual experience with men before. They find an escape from the boredom of life in sex and alcohol. The sex and alcohol enslaves him and makes him lose the authority over his own body. Cynthia's exploitation of his sexuality exhausts and bores him. Gordon rejects and tries to win his body back. He finds a relief when Cynthia suffered from cancer but when Cynthia recovers he is in "danger" of Cynthia's ferocious sexual appetite. Gordon finally lets Cynthia leave him. As Cynthia leaves, he starts his sexual adventure with his long loved sweetheart, Rachel.

Leishman (1999: 193) acknowledges Praise as the pioneer of the new genre in Australian Literature called "grunge". The novel has "uncompromising narratives" that would expose the "raw nerves of youth". It provides an insight of the social phenomenon that was "disturbing but compellingly, unflinchingly real". It was further claimed that" grunge charted the territory of Australia's inner cities and the disenfranchised young people who lived there; gritty, dirty, real existences, eked out in a world of disintegrating futures where the only relief from ever-present boredom was through a nihilistic pursuit of sex, violence, drugs and alcohol".

Exploration and exploitation of the body, sexuality, and disease is dominant throughout the novel. Indeed, the exploitation of the body in the novel presents a wider discourse concerning the social reality present in the contemporary urban Australia particularly and society as a whole. Through the 
exploration of the body, McGahan smartly fabricates the complicated relationship of alcoholism, drug, sexuality and power relation. This essay discusses how the experience of the body reflects and represents the society in which it exists. There are two aspects that I would like to point out here. The first is the power relationship between alcoholism, sex, and patriarchal value, which represents a wider discourse on capitalism, materialism and the second how the disease inflicted in the bodies represent the "destruction" of the society that leads to the degradation of humanity. The basic point is that the body as entity is a microcosm of a larger entity that is society. Any experience concerning the body reflects the reality of the society in which it lives and exists.

\section{BODY AND SOCIETY}

Douglas (2005: 79) explains that the human body is always viewed as images of society. All concerns about body are concerned with social dimension. "Interest in its apertures depends on the pre-occupation with social exits and entrances, escape routes and invasions'. The concern to preserve social boundary is associated with the concern of bodily boundaries. Any social boundary does not exist without the bodily boundaries. The relation between parts of the body, head to feet, brain and sexual organs, mouth and anus "express the relevant pattern of hierarchy". The prospect of imposing body control is futile if there are no corresponding social forms. Lastly, "the same drive that seeks harmoniously to relate the experience of physical and social must affect ideology. Consequently, when once the correspondence between bodily and social controls is traced, the basis will be laid for considering co-varying attitudes in political thought and in theology".

Douglas explains further that the physical body is the representation of the society. It becomes the microcosm of the society. It is affected and constructed by the society

The physical body is a microcosm of the society, facing the centre of power , contracting and expanding its claim in direct accordance with the increase and relaxation of social pressures. Its members, now riveted into attention, now abandoned to their private devices, represent the members of society and their obligations to the whole. At the same time, the physical body, by the purity rule, is polarized conceptually against the social body. Its requirement not only subordinated, they are contrasted with social requirements (2005: 78)

Douglas' idea correponds to Paraceleus doctrine. Paraceleus (in Glausser, 1993: 221) in his doctrine of signature asserts that the condition of individual human body correspond to cosmic condition in their complicated matter and spirit. "A microscopic event, such as epileptic fit, corresponds to macro cosmic event in this case earthquake"

\section{MATERIALIZATION OF THE BODY}

Sawday (2005: 12-26) describes human body as "terra incognita", an unknown land which is free to explore. Through exploration, the body interior becomes too vast, too complex. Then, after the exploration, the body is turned from geographic body into mechanical body. The body is reconstituted. The mechanical body appears fundamentally different from the geographic body. The contour of the geographic body expresses 'a static landscape without dynamic interconnection', while the body as machine, as a clock, as an automation can be understood as 'having no intellect of its own. Instead it silently operated according to the law of machine.

When the geographic is reduced into machine, its resource may be exhausted, its power diminishes. In Marxist sense this refers to the exploitation of human, the materialisation, the machine itself become the means for acquiring capital good, the acquiring of capital to satisfy the materialism. When the body is mechanised, it is used only as a means of material production. In this sense sexual pleasure becomes the outcome produced from the mechanisation of the body. The body is commodified. The exploitation of the body, thus serves as metaphor of capitalist system.

Baudrillard (2005: 277) acknowledges that in capitalist society, the body acquires its general status a private property. It applies to "the way we operate socially with it and the mental representation we have of it. Concerning the body and consumer culture in the capitalist society, he argues that beauty and the erotic function primarily as sign value-the appropriation of the body in consumer culture is no less alienated than the exploitation of the body as labour power. In short, the Narcissistic investment in the body is exactly an investment. It is expected to yield a return, in the form of social status. Based on this reason Baudrillard suggests that 'the cult of the body' should not necessarily be opposed to the 'cult of the soul', but can instead be deemed its successor. The body in consumer culture is viewed as an idea, an abstraction, and equivalent to any other functional object. Thus is consumer culture, the body stands as an independent entity, separated from the mind that inhibits and governs it. 


\section{BODY, SEXUALITY, AND POWER RELATION}

By the depiction of the body and sexuality, McGahan explore the relation between the body and power relation. He focuses on both the dominant and dominated body. The bodily experiences in the novel carry the discourse of power. There is an interplay between the body, the rulers and the ruled, and the dominant and the dominated through the alcoholism and the "ferociousness" of sex which carries a larger discourse concerning patriarchy and capitalism.

Alcoholism creates problem in the life of Gordon and Cynthia. Alcoholism is the problem that influences the body of the character. Both Gordon and Cynthia are alcoholic. The alcohol brings the bad effect to Cynthia. She has skin disease that is caused by her consuming alcohol.

Cynthia's skin got worse. It was all the alcohol and the dust in the flat. At night she rolled over and I scratched the disease on her back until she slept (Praise, p.10)

What happens to Cynthia skin is just the surface effect of her being alcoholic. a Alcoholism not only affects her physical health but also mental. Alcohol degenerate the nervous system, creating a mental disorder that affects individual behaviour. An alcoholic behaviour can be uncontrollable and tends to be aggressive. Kanner describes that alcoholism is a pathological definition. Alcohol itself is toxin, which, when introduced to human body in sufficient amount in a long period of time will result in the degeneration of major organ system. Recent evident proves that alcohol affect female physiology in the different ways as it affects males. Alcoholism requires the investment of considerable socio-cultural energy in combating and managing its manifestation (Kanner, 1993: 174).

The expression of an unfettered and unrestrained social and emotional self often stimulated by the consumption of alcohol, is among the most provocative and dangerous characteristics of alcoholic woman. The text requires the audience simultaneously to read this danger and construct the woman alcoholism in ways that requires immediate intervention, that attempt silence and control the extremes of emotion and the assertion of autonomy displayed by the alcoholic woman (2007: 161).

Cynthia's alcoholism serves as a complex representative function of deconstructing gender. It is not merely a case degeneration of body organ that become the crucial issue in this novel. Cynthia and Gordon are depicted as alcoholic but Cynthia is represented as worse than Gordon. She suffers a disease that is likely to results from her being an alcoholic. Cynthia's addiction to alcohol is parallel to her addiction of sex. She has prolific sexual experience with men. Cynthia's alcoholism function as what Kanner refers to as political strategy, "challenging the prevailing social order and providing temporary access to hidden meaning." Kanner asserts (1993: 158) that 'becoming of being an alcoholic is neither motivated nor volitional-such act obviously involves considerable individual and social cost.

As alcohol degenerate the nervous system and make one lose control over oneself, so does sex. Inability to control sexual desire is comparable to the loss of emotional control due to drunkenness. The sexual pleasure itself is comparable to the addiction of drug. In the drug, alcohol and sex are the means of escape from boredom and the uncertain life. Drug, alcohol, and sex offered a temporary escape from the burden of life. However those three cannot offer more than just pleasure, more importantly they make the life of the characters deteriorates as their health decline.

Cynthia's aggressiveness and sexual domination embodies the discourse of Patriarchal domination. In this narrative, alcoholism serves as vehicle that carries the discourse of reversal gender role. It becomes complicated when the masculine characteristic exist in Cynthia. This reversal of role is obvious in the relationship between Cynthia and Gordon. Cynthia is "more man" than Gordon. She is aggressive and dominant, while Gordon is vulnerable and more sober. It also signified that gender role is not naturally inherent, instead it is constructed. The difference between Gordon and Cynthia's attitude suggests masculine characteristic is inherent on female and vice versa. The reversal of gender role is also represented through their consumption of food. Cynthia's consuming food suggests her masculine trait and reflects her sexuality.

There was no food in the fridge. Cynthia felt like steak. She was a big meat eater. Steak and chicken. I preferred sausages, or pasta, or Chinese. Things you didn't have to chew. [...]

The meals came. Cynthia got her steak. It was big She had a plate of fat fried chips with it. She wolfed it down. She could eat. I was having fish. A delicate little fillet in light sauce. With salad. It was all the wrong way around. Cynthia was more of a man than I was. (Praise, p.89) 
Cynthia's preference for meat represents the patriarchal value that is identical with ferociousness and aggressiveness. Carole Adam in her Article The sexual Politic of meats point out that the act of eating meat represent male power. Adams suggest that Women and animals are the 'voiceless' victims of patriarchy. Adams reiterated endlessly that 'Eating animals act as a mirror and representation of patriarchal values'. In fact it does not seem to matter whether it is animal or woman that is the object of consumption because 'meat eating is the re-inscription of male power at every meal'. This yields a direct equation of the terms meat and men, which then can be inverted at will: "they killed and slaughter animal yields....imagery of ferociousness, territorial imperative, armed hunting, aggressive behaviour, the vitality and virility of meat eating" (Praise, p.84)

Barthes (in Probyn, 2005: 164) acknowledges that 'food has a constant tendency to transform itself into situation. Food is always 'bound to values of power', revealing the fact that 'a representation of contemporary existence is implied in the consciousness we have of the function of food'. The act of transgression and ferociousness leads to a discourse of colonial power, the power to invade other's body, in this case is the feminine body. Hence, the body is viewed as a geographic entity to invade and colonies, as a frontier to explore and exploit. The aggressiveness of Cynthia represents the invasive colonial power. Her dominant power leads to invasion of Gordon's body. Gordon body serves as what Sawday (2005: 20) refers to as "terra incognita" for Cynthia to explore. It is a virgin land which is open for exploration. Thus, Gordon's body become a geographic entity that offers opportunity for Cynthia to gain pleasure. Gordon's body is then mechanised as it is operated to satisfy Cynthia's ferocious sexual desire. The exploitation of Gordon's body by Cynthia represents the labour exploitation in capitalist system. Human labour is exploited for the profit of the capital owner, who holds the dominant power. The system works for the interest of the capital holder. The human labours are treated like a production machine. Alcoholism itself is a product and a link to a complex capitalist industry, as much a part of society as sobriety. In this sense, the capitalist system is a form of slavery, which deprives human labour from their freedom. Gordon's resigning from his job in the bottle shop represent the author's rejection on the capitalistic system. The system is not fair as it demands too much from the labour something that is more than the job was worth.

Working in a pub, or any retail business, was at best dreary and mindless existence. To be merely competent at it-to refrain, say, from abusing forty or fifty percent of your customers-often took a soul destroying effort. To have enthusiasm demanded of you, that was more than the job was worth. (Praise, p.33)

The image of the body as machinery is further represented in the porn magazines that were sent by Harry, Gordon's friends, in which women bodies are fetishises. In the pornography business, image of body and sexuality are the main commodity, which is sold to satisfy public fantasy on sexuality. Another form of the exploitation of body is the program on Sky TV, in which women's bodies determined their values.

...it was sky TV and tonight there was a talent show called 'Best chest in the U.S.'. I picked up the format after a few minutes. There were six categories in which a woman could compete, based on the size of her breasts. The first heat was for the smaller women, and then the categories went up by bra size, until up in the sixth it was for the 38Ds and above. Or something like that. I knew nothing about bra sizes. I only knew that the breasts got larger and larger as the show progressed. There were six entrants in each category. It was held before a lived studio audience, with a panel of judges. Each contestant had about twenty seconds to get on stage, dance around and rip off her top. Then the judge gave a score (Praise, p.3)

The text also demonstrates a complex relationship between the body and consumer culture. In the case of "Best chest in the U.S' program, bodies are opened up to consumers choice. The boundaries between "nature" and "cultural" is redefined as they set up the standard for scoring.

Body itself is the private territory that human being posses. When body as the boundary between self and society falls into the hands of others the person lose control over his/her own territory. Gordon loses his authority over his own territory as his body is possessed by Cynthia. Cynthia's exploitation of Gordon's body suggests the invasion of the territory. Gordon's desire to free himself from Cynthia's domination conveys his consciousness of his body as his own property instead of Cynthia's. Cynthia's possession of his body is seen as violation of this right.

The place where Gordon lives provides a parallel metaphor as the body. The apartment epitomise how a private space, a body, has lost its personal autonomy. Everybody in the apartment can get into other's flat easily using their own key. 
My room was two doors up, and everyone's keys fitted everyone else's doors. I was always surprised that no one went into my rooms when I was out. I had a TV in there, and food. and very often beer in the fridge, but things only occasionally went missing. Mostly it was clothes. (Praise, p.3)

Here, the private sphere is "trespassed" and the private property in this sense can be other's property just like Gordon's body becomes the property of Cynthia. Gordon's loss of his autonomy on his own body is parallel to the loss that Vass suffer after his TV and tape were stolen by other resident.

\section{THE SICK BODY AS A METAPHOR}

When the body is mechanised and commoditize its meaning is reduced to merely material thing. When things are materialised, it lost its value. And the degradation of the body values implies the degradation of humanity to merely material. The loss of meaning is represented in Cynthia's body. She is betrayed by her own body. Having prolific sexual experience, she is inflicted by cervical cancer. She also transfers warts to Gordon through their sexual intercourse.

The disease itself epitomises the excess of a complex system that has embodied the society for ages. It is the excess of capitalism that has materialised human body as merely as object, as the means of production, thus separate it from the mind that is supposed to govern and works to keep its harmony. Sheikh Nuruddin (Bin Hassan Mydin Abdullah \& Bin Ismail, 2010: 7) asserts that naturally human consist of body and soul, which are inseparable. Those two entities are what creates human. They should work together in harmony, as a system. When they are separated, there is a danger of the destruction of the self. Indeed, when human lose possession over his/her own body he/she fall he/she will lose the autonomy over his/her own self.

Gilman (in Sauer, 1993: 74) points out that illness is related not only with death but also with the human experience of impotence or limited control of life and the world. The depiction of illness serves as psychological function in literary works:

The fear that we have of our own collapse does not remain internalized. Rather, we project this fear onto the world in order to localize it and indeed, to domesticate it ...Illness is a real loss of control that results in our being the other whom we have feared. ..Disease, with its seeming randomness, is one aspect of the indeterminable universe that we wish to distance from ourselves.

For Cynthia the cervical cancer that inhibit her body brings a paranoia, the fear of death and the fear that her body can no longer function and lose its meaning. When her body ceases to function, it means that she loses her identity, her existence. Cynthia existence is defined by her body and sexuality, therefore the disfunctioning of her body is a threat for her. She takes the doctor warning not to have sex for one month seriously for fear of a greater loss, the loss of power.

The cancer in Cynthia's body has dual function. It represents a complex discourse. It stands for the patriarchal power in Cynthia's self, a destructive power that invades not only Gordon private property but also her own self. It signifies the counter attack force that combats and defeats her sexual desire. When the force is gone after the operation, she can win back her sexual possession. Gordon regaining his body after Cynthia leaving for Darwin is like the achieving freedom from colonisation. However, he is not totally free as there is still another cancer inflicted in his body, the emptiness of life, that lead him to find escape in alcohol and sex.

Cancer is associated with colonial forces that attack and invade a territory; in this sense is the body. It has a destructive power that attacks the system, resulting in the systemic failure. To save the territory from the destruction there is no other way but combating it with a counter attack force. Radioactive treatment is the counter attack forces (Sontag, 1995). The invasion of cervical cancer in Cynthia's body presents a parallel to Cynthia's invasion on Gordon's body. It is a colonial power that must be resisted. The operation is the resistance to the invading force. The combating of disease through medical treatment turns the body into a battle ground. It is the battle of good against evil.

Frank (2007: 217) asserts that when illness occurs, the disease carries a 'metonymic overload that compounds suffering. The disease is real in itself. It is like the tips of an iceberg. Disease, particularly the sexual transmitted disease, is only one visible aspect of a larger complex phenomenon in the society. It presents a metonymy, in that it stands for a larger whole, suggesting some external threats. Some of these threats are related to the spread of disease itself. The spread of sexually transmitted disease is what the physicians worry about. "The losses brought by the disease open up extensive fears that one's intactness has always been more imaginary than the self wanted to believe." Disease is 'all too effective as a journalistic metaphor for social problem-crime, poverty, drug use, inflation-because disease metaphor tap the intuitive connection between internal threats to the body. 


\section{CONCLUSION}

In conclusion, all the bodily experiences of the character in the novel, particularly those concerning the sexuality represents the complex discourse of power relationship that includes patriarchy, colonialism and capitalism in the contemporary society. The power invades and corrupts the body and the society and brings disorder. The corruption results in the disease that inflicts the characters, which ruin their systemic function. The "destruction" of the body represents the complicated problems in the society as a result of capitalist system. The "destruction" of the body represents the degradation of the society.Through a set of metaphors in the narrative, the author successfully fabricates a parallel interplay of the alcoholism, sexuality and the disease, that signifies the complexity of the problem inherent in the society in particular and human life in general.

Using the body as metaphors, McGahan presents what is referred to by Bakhtin as "grotesque realism". The result of the grotesque realism is the "material body principle". Bakhtin explains that the principle of grotesque realism is degradation, that is "lowering of all that is high and spiritual, ideal, abstract: it is a transfer to the material level, to the sphere of earth and body in their indissoluble unity....Not only parody in its narrow sense but all the other forms of grotesque realism degrade, bring down to earth, turn their subject into flesh." ( in Morrow, 1992: 37). MacGahan brings readers closer to experience the reality that is kept overt, making the unknown phenomenon appear like an iceberg. He tries to uncover the overt reality that is unseen to make readers realise that there is a complex phenomenon lies under the tip of the iceberg which is worse than what people know as he uncovers the make up that Cynthia wears to conceal her skin disease. The author strips off the mask of the materialised society and demonstrate the dark side of human life in the contemporary culture.

\section{REFERENCES}

Bakhtin, Mikhail. (2005). The Grotesque image of the Body and Its Sources. In Mariam Fraser and Monica Greco (eds). The Body. London and New York: Routledge.

Baudrillard, Jean. (2005). The Finest Consumer Object. In Mariam Fraser and Monica Greco (eds). The Body. London and New York: Routledge. pp. 277-282.

Bin Hassan Mydin Abdullah, Shaik Abdullah \& Dr. Issham Bin Ismail. (2015). "Konsep Pembangunan Modal Insan Berkiblatkan Ajaran Islam (The Concept of Human Development Based on Islamic Teaching)", pp.1-22. in http://pkukmweb.ukm.my/ pkaukm/BUKU\%201\%20\&\%202/ PDF_buku\%201/C18_Shaik\%20USM_Modal\%20Insan.pdf. Accessed 22 July 2010.

Day, Frank. (2006). Illness as Metaphor. Masterplots II: Women's Literature Series. Salem Press, 1995. eNotes.com <http://www.enotes.com/illness-metaphor-salem/illness-metaphor-9610000235, accessed 19 June 2010

Douglas, Mary. (2005). "The Two Bodies", in The Body, eds. Mariam Fraser and Monica Greco. 2005. London and New York: Routledge.

Frank, Arthur. (2005). The Self Unmade. Embodied Paranoia. In Mariam Fraser and Monica Greco (eds). The Body. London and New York: Routledge.

Glausser, Wayne. (1993). Locke and Blake as Physician: Delivering the Eighteen Century Body. In Catherine B. Burroughs and Jeffrey David Ehrenreich (eds.), Reading the Social Body, pp. 218243. lowa City: University of lowa Press.

Kanner, Melinda. (1993). "Drinking Themselves to Life, or the Body in the Bottle, Filmic Negotiations in the Construction of the Alcoholic Female Body. In Catherine B. Burroughs and Jeffrey David Ehrenreich (eds.), Reading the Social Body, pp. 156-184. lowa City: University of lowa Press.

Leishman, Kirsty. (1999). "Australian Grunge Literature and the Conflict Between Literary Generation" [Paper in: Writing Australia: New Talents 21C, Murphy, Ffion (ed.).] [online], Journal of Australian Studies, no.63, 1999: (94)-102, pp. 193-195.

Mc Gahan, Andrew. (1992). Praise. Crows Nest: Allen and Unwin, repr. 2005.

Morrow, Raymond. (1992). A.Patriarchal Bodies and Pre Modern Subjects: Grotesque Realism and Domination in Garcia Marquez's El Otono Del Patriarca. In Anthony Purdy (ed.), Literature and the Body, pp. 29-52. Amsterdam-Atlanta: Rodopi.

Probyn, Elspeth. (2005). Beyond Food and sex: Eating and a Ethics of Existence. In Tiffany Atkinson (ed.), The Body, pp. 156-166. New York: Palgrave Macmillan.

Sauer, Pamela S. (1993).The triumph of Sickness in Modern Austrian Literature. In David Bevan(ed.), Literature and Sickness, pp. 53-75. Amsterdam-Atlanta: Rodopi.

Sawday, Jonathan. (2005). The Renaissance Body: From Colonisasion to Invention. In Tiffany Atkinson (ed.), The Body, pp. 12-26. New York: Palgrave Macmillan. 